\title{
EFFECT OF WATER SOLUBLE POLYMER AND FIBER ON THE EARLY-AGE SHRINKAGE CRACKING OF CEMENTITIOUS COMPOSITES
}

Shih-Tang Lin

Nan Shing Color Co., Ltd., Taipei, Taiwan; College of Engineering, Tatung University, Taipei, Taiwan, R.O.C.

Ran Huang

Institute of Materials Engineering, National Taiwan Ocean University, Keelung, Taiwan, R.O.C., ranhuang@mail.ntou.edu.tw

Tsai-Lung Weng

Physics Division, Tatung University, Taipei, Taiwan, R.O.C.

Follow this and additional works at: https://jmstt.ntou.edu.tw/journal

Part of the Civil and Environmental Engineering Commons

\section{Recommended Citation}

Lin, Shih-Tang; Huang, Ran; and Weng, Tsai-Lung (2012) "EFFECT OF WATER SOLUBLE POLYMER AND FIBER ON THE EARLY-AGE SHRINKAGE CRACKING OF CEMENTITIOUS COMPOSITES," Journal of Marine Science and Technology.

Vol. 20: Iss. 3, Article 8.

DOI: $10.51400 / 2709-6998.1807$

Available at: https://jmstt.ntou.edu.tw/journal/vol20/iss3/8

This Research Article is brought to you for free and open access by Journal of Marine Science and Technology. It has been accepted for inclusion in Journal of Marine Science and Technology by an authorized editor of Journal of Marine Science and Technology. 
EFFECT OF WATER SOLUBLE POLYMER AND FIBER ON THE EARLY-AGE SHRINKAGE CRACKING OF CEMENTITIOUS COMPOSITES

Acknowledgements

We would like to gratefully acknowledge the National Science Council for the financial support (NSC 96-2622E019-005-cc3). 


\title{
EFFECT OF WATER SOLUBLE POLYMER AND FIBER ON THE EARLY-AGE SHRINKAGE CRACKING OF CEMENTITIOUS COMPOSITES
}

\author{
Shih-Tang Lin $^{1}$, Ran Huang ${ }^{2}$, and Tsai-Lung Weng ${ }^{3}$
}

Key words: aspect ratio, fiber spacing, fiber-matrix bond, crackbridging.

\begin{abstract}
Both polymeric fiber and water soluble polymer (WSP) have been reported effective in reducing early-age shrinkage cracking. The synergistic effect of cellulose based WSP and fiber on reducing early-age shrinkage cracking of cementitious composite exposed to a constant evaporation rate of $1 \mathrm{~kg} /($ h.m2) environment was investigated in this paper. A fixed ratio of WSP was employed in the poly-acrylic fiber reinforced cementitious composites with various fiber content and aspect ratios. Results indicate that the addition of polymeric fibers reduced plastic shrinkage cracking, such as the total crack area, the average crack width and cracks wider than $1.5 \mathrm{~mm}$. Further reductions on both the crack width and the total crack area were achieved when WSP was used in combination with fibers with an aspect ratio of less than 420. The synergistic reduction on the early-age shrinkage cracking may be attributed to the improvement of the fiber-matrix bond strength and polymer film formation on the drying front. Nevertheless, when fibers with an aspect ratio greater than 420 the synergistic effect provided by the WSP might be masked by the decreased fiber spacing or stronger crackbridging capability. In practical terms, preventing early-age shrinkage cracking by adding WSP not only can reduce fiber requirement but may also keep mixture workable.
\end{abstract}

\section{INTRODUCTION}

Shrinkage deformation is an inherent weakness of concrete.

Paper submitted 01/22/11; revised 01/11/12; accepted 04/11/12. Author for correspondence: Ran Huang (e-mail: ranhuang@mail.ntou.edu.tw).

${ }^{I}$ Nan Shing Color Co., Ltd., Taipei, Taiwan; College of Engineering, Tatung University, Taipei, Taiwan, R.O.C.

${ }^{2}$ Institute of Materials Engineering, National Taiwan Ocean University, Keelung, Taiwan, R.O.C.

${ }_{3}^{3}$ Physics Division, Tatung University, Taipei, Taiwan, R.O.C.
The absolute volume of the hydrated concrete is less than the total volume of the constituents before hydration. After setting, concrete may undergo considerable irreversible drying shrinkage. Nevertheless, shrinkage cracking occurs more often at an early-age because young concrete has not developed enough strength to withstand the restraint-induced stress. Restrained shrinkage cracks range from invisible micro cracks to visible macro cracks. Invisible and hairy cracks may expand and propagate in the long term due to drying shrinkage or creep deformation. Furthermore, cracks would allow aggressive agents to reach and corrode the rebar easily, and thus reduce its service life. The durability of reinforced concrete is therefore seriously affected and the merit of using concrete as a durable material is therefore totally negated.

Adding discrete short fibers in the composite to withstand the crack driving force has been reported effective on reducing plastic shrinkage cracking [1]. Nevertheless, randomly distributed fibers may hinder the movement of cementitious particles and aggregates, and thus reduce the workability of the fresh concrete [3,13]. The effectiveness of fibers on reducing cracking depends not only on the fiber volume [14] but also on the interfacial bond between cementitious matrix and fibers $[6,15]$. Adding polyvinyl alcohol (PVA), a type of water soluble polymer (WSP), has been reported effective on improving the steel fiber- matrix interfacial bond strength, and thereby increasing cracking resistance $[6,15]$. In the same manner, Methyl Cellulose, a cellulosic WSP, has been reported effective on enhancing the interfacial bond between carbon fibers and the cementitious matrix $[5,7,18]$. Addition of Hydroxy Propyl Methyl Cellulose (HPMC) in the cementitious composite was reported to be effective in reducing early age shrinkage cracking [9-11] due to the polymer film formation and deposition of fine particles on the drying front of the cementitious matrix [4]. This study explores if a synergistic reduction of early-age cracking exists between polyacrylic fibers and HPMC based WSP. The hypothesis is that the polymer films may form in the fiber-matrix interface, and thereby increase fiber-matrix bond strength or friction so that more cracking energy would be dissipated. As a result, crack width and the total crack area could be reduced. 
Table 1. Properties of fibers [16].

\begin{tabular}{lcccc}
\hline Designation & AX & BX & CX & BY \\
\hline Cut length $(\mathrm{mm})(l)$ & 4 & 6 & 8 & 6 \\
\hline Fiber diameter $(\mu \mathrm{m})(d)$ & 14.3 & 14.3 & 14.3 & 26.8 \\
\hline Aspect ratio $(l / d)$ & 280 & 420 & 560 & 224 \\
\hline Quantity of fibers/gram & $1320 \mathrm{~K}$ & $877 \mathrm{~K}$ & $660 \mathrm{~K}$ & $249 \mathrm{~K}$ \\
\hline Specific weight $\left(\mathrm{g} / \mathrm{cm}^{3}\right)$ & 1.18 & 1.18 & 1.18 & 1.18 \\
\hline Fiber tensile strength $(\mathrm{MPa})$ & 570 & 570 & 570 & 490 \\
\hline Fiber E-modulus $(\mathrm{GPa})$ & 10.6 & 10.6 & 10.6 & 10.1 \\
\hline Fiber elongation $(\%)$ & 15 & 15 & 15 & 18 \\
\hline
\end{tabular}

A cellulosic HPMC was employed with a fixed weight ratio of cement [9] in fiber reinforced mortar specimens containing various aspect ratios of alkali-resistant polyacrylic fibers. An environmental chamber was constructed to provide designated exposure condition [2] to assess early-age shrinkage crack areas and crack width distribution. The effects of fibers and combination of fibers and WSP on the total crack areas (TCA), average crack width $(\mathrm{ACW})$, and crack width distribution were examined. Micrographs were observed, and the mechanism for the synergistic reduction on early-age shrinkage cracking between WSP and fibers was also investigated.

\section{EXPERIMENTAL PROGRAM}

\section{Materials}

The fibers used are the alkaline resistant polyacrylic fibers with special bundle treatment for accurate weighing and conveying for the dry mortar industry. The physical and mechanical properties of fibers are summarized in Table 1 [16]. The dosage of WSP was selected based on previous studies [9, 10]. Details of WSP (HPMC) are listed in Table 2 [17].

\section{Mixture Proportions}

Type I Portland cement with the Blaine fineness of 360 $\mathrm{m}^{2} / \mathrm{kg}$ and silica sand with a size less than $250 \mu \mathrm{m}$ was used. Four aspect ratio polyacrylic fibers with fiber content from 0.1 to $0.3 \%$ (by cement weight) were included in the mortar mixtures. A selected WSP powder [9] was added to the fiber reinforced mortars to investigate the possible synergistic reduction of cracking tendency. The mixture proportions were summarized in Table 3. Fibers, WSP powder, cement, and sand were pre-mixed by a pan mixer with rpm 26 for 3 minutes. Then water was slowly added to the mixer for another 3 minutes or until a homogeneous composite was observed.

\section{Test Methods, Procedures, and Equipments}

\section{1) Plastic Shrinkage Cracking}

The plate mold for the specimen was $600 \times 600 \times 40 \mathrm{~mm}$ with sixteen $\varphi 10 \times 200 \mathrm{~mm}$ threaded steel to provide the boundary restraint and differential depth as shown in Fig. 1.
Table 2. Deatails of WSP (HPMC) [7].

\begin{tabular}{lc}
\hline Designation & WSP \\
\hline Chemical composition & HPMC \\
\hline Molecular Weight $(\mathrm{g} / \mathrm{mol})$ & $12-16 \mathrm{~K}$ \\
\hline Viscosity (cps at $20^{\circ} \mathrm{C}, 2 \mathrm{wt} \%$ solution) & 5 \\
\hline Specific weight & 1.26 \\
\hline Appearance & Off-white powder \\
\hline
\end{tabular}

For each mixture, two plate specimens were tested. An environmental chamber equipped with a speed adjustable fan and other necessary devices was specially constructed to keep the evaporation rate of water in a monitoring pan at $1000 \mathrm{~g} / \mathrm{m}^{2} . \mathrm{h} \pm$ $10 \%$ as shown in Fig. 2 and to meet the specifications of ASTM C1579-06 [2]. The complete setups of plate and environmental chamber have been fully described in a previous study [9].

\section{2) Quantification of Early-age Shrinkage Cracking}

Crack lengths were determined by a wet string attached along the crack line 24 hours after the air flow test. Crack widths were manually measured by a calibrated crack comparator every $25 \mathrm{~mm}$ along the crack lines. The average line crack width (Wn) was the summation of measured crack widths in one line divided by the number of measurements. The line crack area (An) was obtained by multiplying the average line crack width (Wn) by the line crack length (Ln). The total crack area (TCA) was defined as the summation of all the line crack areas in a plate specimen.

The total crack area (TCA) divided by the total line crack length ( $\mathrm{Ln})$ was defined as the average crack width (ACW).

$$
A C W=\frac{T C A}{\sum L n}
$$

\section{RESULTS AND DISCUSSION}

Typical cracking pattern of the plate specimens are illustrated in Figs. 3-5. Early-age shrinkage cracking test results such as TCA, ACW, and crack width distribution are reported as the average of two specimens as summarized in Table 4. The aspect ratio $(l / d)$ of a fiber is calculated by dividing the fiber length $(l)$ by its diameter $(d)$ The longer the fiber is, and/or the smaller the diameter of the fiber, the higher the aspect ratio is.

\section{Influence of Fiber and Fiber Aspect Ratio on the Total Crack Area}

The total crack area (TCA) was the summation of the line crack areas. In general, the TCA was effectively reduced in the specimens with fibers and the reduction efficiency depended on the fiber content as shown in Fig. 6.

The reference mixture $(\mathrm{R})$ had the largest TCA of 3647 
Table 3. Mixture proportion $\left(\mathrm{kg} / \mathrm{m}^{3}\right)$.

\begin{tabular}{|c|c|c|c|c|c|}
\hline Mixture designation & Cement & Silica sand & Water & $\begin{array}{c}\text { Fiber volume } \\
(\%, \text { by weight of cement })\end{array}$ & $\begin{array}{c}\text { WSP dosage } \\
\text { (\%, by weight of cement })\end{array}$ \\
\hline $\mathrm{R}$ & 833.9 & 833.9 & 417.0 & 0 & 0 \\
\hline AX1 & 833.3 & 83.3 & 416.7 & 0.1 & 0 \\
\hline $\mathrm{AX} 2$ & 832.8 & 832.8 & 416.4 & 0.2 & 0 \\
\hline AX3 & 832.2 & 832.2 & 416.1 & 0.3 & 0 \\
\hline $\mathrm{BX} 1$ & 833.3 & 83.3 & 416.7 & 0.1 & 0 \\
\hline $\mathrm{BX} 2$ & 832.8 & 832.8 & 416.4 & 0.2 & 0 \\
\hline $\mathrm{BX} 3$ & 832.2 & 832.2 & 416.1 & 0.3 & 0 \\
\hline CX1 & 833.3 & 83.3 & 416.7 & 0.1 & 0 \\
\hline $\mathrm{CX} 2$ & 832.8 & 832.8 & 416.4 & 0.2 & 0 \\
\hline $\mathrm{CX} 3$ & 832.2 & 832.2 & 416.1 & 0.3 & 0 \\
\hline BY1 & 833.3 & 83.3 & 416.7 & 0.1 & 0 \\
\hline BY2 & 832.8 & 832.8 & 416.4 & 0.2 & 0 \\
\hline BY3 & 832.2 & 832.2 & 416.1 & 0.3 & 0 \\
\hline BY4 & 831.6 & 831.6 & 415.8 & 0.4 & 0 \\
\hline BY5 & 831.0 & 831.0 & 415.5 & 0.5 & 0 \\
\hline AX1-W & 831.7 & 831.7 & 415.8 & 0.1 & 0.3 \\
\hline AX2-W & 831.1 & 831.1 & 415.6 & 0.2 & 0.3 \\
\hline AX3-W & 830.5 & 830.5 & 415.3 & 0.3 & 0.3 \\
\hline BX1-W & 831.7 & 831.7 & 415.8 & 0.1 & 0.3 \\
\hline BX2-W & 831.1 & 831.1 & 415.6 & 0.2 & 0.3 \\
\hline BX3-W & 830.5 & 830.5 & 415.3 & 0.3 & 0.3 \\
\hline CX1-W & 831.7 & 831.7 & 415.8 & 0.1 & 0.3 \\
\hline CX2-W & 831.1 & 831.1 & 415.6 & 0.2 & 0.3 \\
\hline CX3-W & 830.5 & 830.5 & 415.3 & 0.3 & 0.3 \\
\hline BY1-W & 831.7 & 831.7 & 415.8 & 0.1 & 0.3 \\
\hline BY2-W & 831.1 & 831.1 & 415.6 & 0.2 & 0.3 \\
\hline BY3-W & 830.5 & 830.5 & 415.3 & 0.3 & 0.3 \\
\hline
\end{tabular}

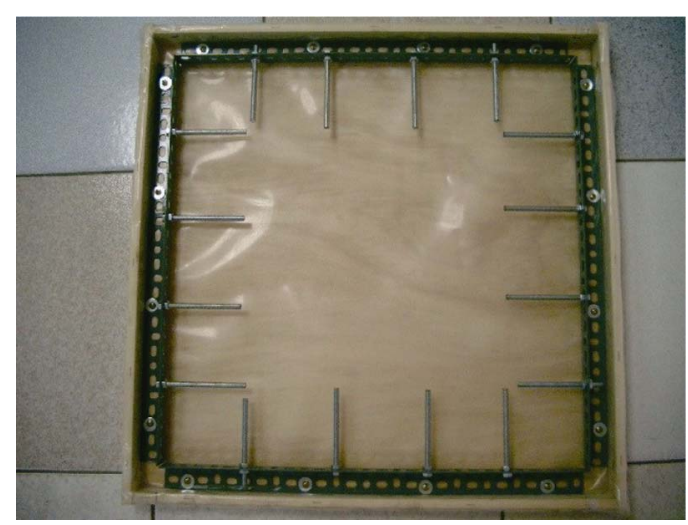

Fig. 1. Plate mold for plastic shrinkage cracking.

$\mathrm{mm}^{2}$. With the inclusion of $0.1 \%$ fibers (wt.\% of cement) in the mixture, the TCAs of BY1, AX1, BX1, CX1 are reduced to $3095 \mathrm{~mm}^{2}, 2752 \mathrm{~mm}^{2}, 1281 \mathrm{~mm}^{2}$, and $1272 \mathrm{~mm}^{2}$, respectively.

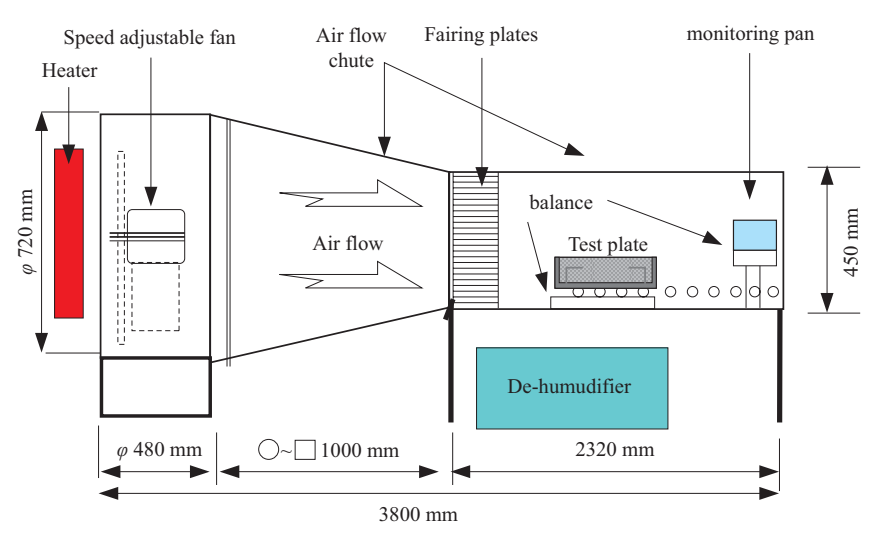

Fig. 2. Schematic illustration of the environmental chamber.

With the addition of $0.2 \%$ fibers, the TCAs reduced drastically to $2149 \mathrm{~mm}^{2}$ (BY2), $1618 \mathrm{~mm}^{2}$ (AX2), $1282 \mathrm{~mm}^{2}$ (BX2), and $68 \mathrm{~mm}^{2}$ (CX2), respectively. No cracking was observed when 


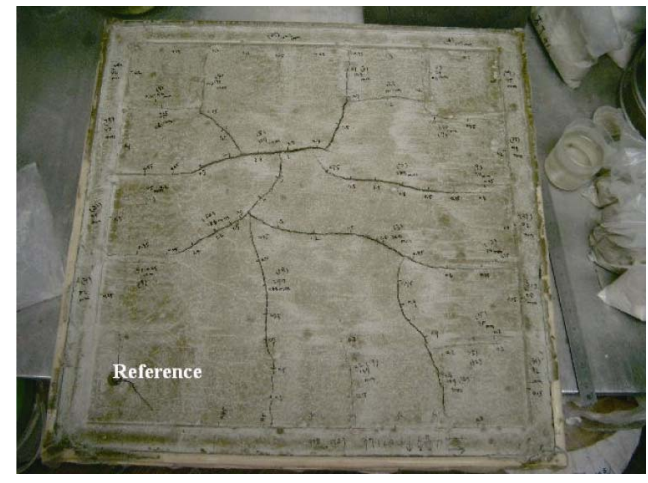

Fig. 3. Cracking of reference specimen.

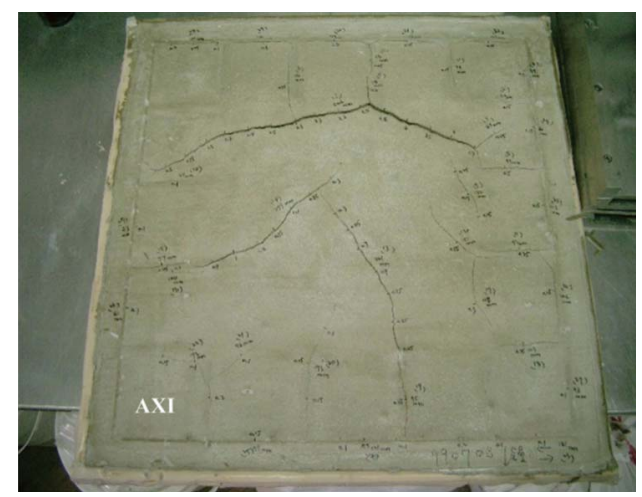

(a)

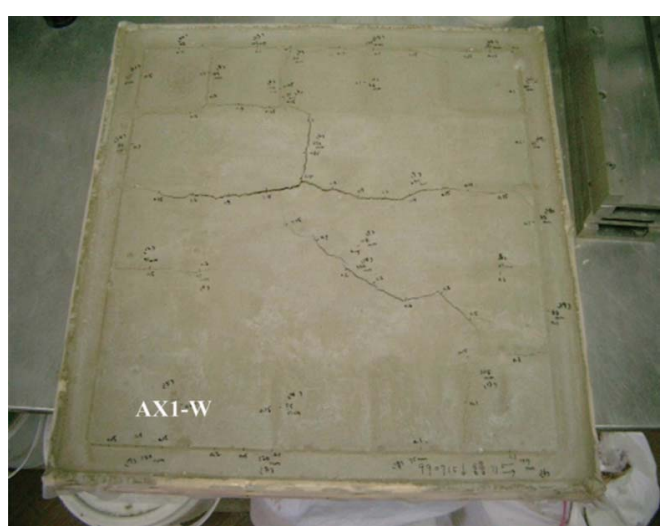

(b)

Fig. 4. (a) Cracking of AX1 specimen and (b) Cracking of AX1-W specimen.

$0.3 \%$ of BY3 and CX3 were included. These results suggest that the fiber content affects the TCA significantly.

The TCA was also affected by the aspect ratio. As the aspect ratio increased, the TCA reduced as depicted in Fig. 7.

The AX, BX, and CX had the same diameter of $14.6 \mu \mathrm{m}$, but the fiber lengths were $4 \mathrm{~mm}, 6 \mathrm{~mm}$, and $8 \mathrm{~mm}$, respectively. Given the same weight inclusion of fibers, the length of fiber reduced the TCA more effectively. For example, with the inclusion of $0.2 \%$ fibers, the $8 \mathrm{~mm}$-long CX fiber had the TCA of $68 \mathrm{~mm}^{2}$, while the $4 \mathrm{~mm}$-long AX fiber had the TCA of

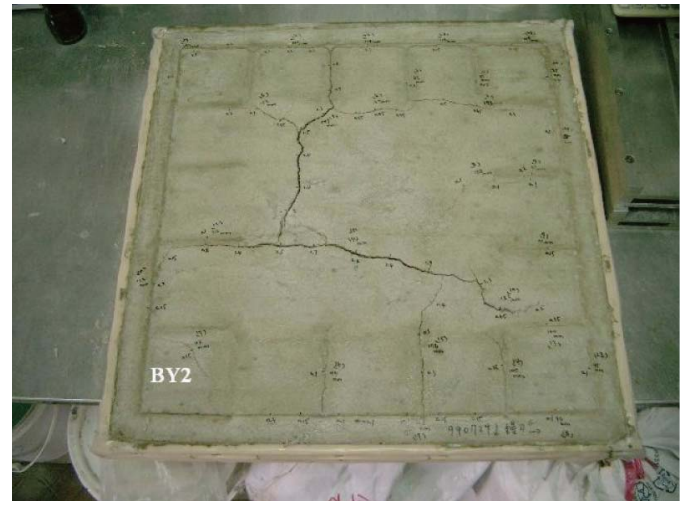

(a)

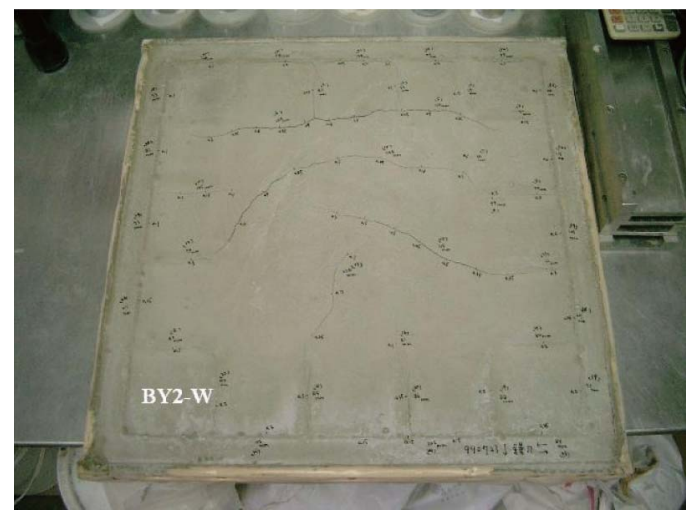

(b)

Fig. 5. (a) Cracking of BY2 specimen and (b) Cracking of BY2-W specimen.

$1618 \mathrm{~mm}^{2}$ and the $6 \mathrm{~mm}$-long BX fiber had $1282 \mathrm{~mm}^{2}$. Similar trends were observed in the inclusion of fibers at $0.1 \%$ and $0.3 \%$ dosage. This improvement might have resulted from better cracking-bridging capacity provided by longer fibers. By the same token, the diameter of fiber influenced the TCA as well. BX and BY had the same length of $6 \mathrm{~mm}$ but differed in diameters. The diameter of BY was two times that of BX.

Nevertheless, with the inclusion of coarse fibers, the TCAs were $3095 \mathrm{~mm}^{2}$ (BY1), $2149 \mathrm{~mm}^{2}$ (BY2), and $1090 \mathrm{~mm}^{2}$ (BY3), which more than doubled those of BX1 $\left(1281 \mathrm{~mm}^{2}\right)$, BX2 $\left(537 \mathrm{~mm}^{2}\right)$, and BX3 $\left(0 \mathrm{~mm}^{2}\right)$, respectively. Consequently, these results suggest that fibers with smaller diameters inhibit cracking more effectively than coarse fibers. This could be explained by the decreasing fiber spacing due to the inclusion of 4 times of BX fibers. Because the aspect ratio (1/d) was obtained by dividing the fiber length by the fiber diameter, a longer and finer fiber yielded a higher aspect ratio. (Thus, as the aspect ratio of the fiber increased, the TCA decreased.) Consequently, the reduction of early-age cracking or TCA was significantly affected by the fiber content and the aspect ratio of fiber. The more the fiber content and the larger the aspect ratio of a fiber, the better crack resistance of mixture might be achieved. 
Table 4. Summary of plastic shrinkage cracking test results.

\begin{tabular}{|c|c|c|c|c|c|c|c|}
\hline \multirow{2}{*}{ Designation } & \multirow{2}{*}{\begin{tabular}{|c|}
$\begin{array}{c}\text { Total crack area } \\
(\mathrm{TCA})\left(\mathrm{mm}^{2}\right)\end{array}$ \\
\end{tabular}} & \multicolumn{4}{|c|}{ Total crack area $\left(\mathrm{mm}^{2}\right)$ grouped by crack width* } & \multirow{2}{*}{$\begin{array}{l}\text { Average crack width } \\
(\mathrm{ACW})(\mathrm{mm})\end{array}$} & \multirow{2}{*}{$\begin{array}{l}\text { Total crack length } \\
(\mathrm{TCL})(\mathrm{mm})\end{array}$} \\
\hline & & $<0.50 \mathrm{~mm}$ & $0.51-1.00 \mathrm{~mm}$ & $1.01-1.50 \mathrm{~mm}$ & $>1.50 \mathrm{~mm}$ & & \\
\hline $\mathrm{R}$ & 3647 & 428 & 638 & 710 & 1872 & 0.90 & 4124 \\
\hline $\mathrm{AX} 1$ & 2752 & 690 & 421 & 270 & 1370 & 0.64 & 4354 \\
\hline $\mathrm{AX} 2$ & 1618 & 517 & 310 & 326 & 466 & 0.5 & 3243 \\
\hline $\mathrm{AX} 3$ & 365 & 165 & 200 & 0 & 0 & 0.32 & 1252 \\
\hline $\mathrm{BX} 1$ & 1281 & 237 & 454 & 249 & 0 & 0.49 & 2605 \\
\hline $\mathrm{BX} 2$ & 537 & 87 & 134 & 0 & 0 & 0.58 & 926 \\
\hline $\mathrm{BX} 3$ & 0 & 0 & 0 & 0 & 0 & 0.00 & 0 \\
\hline CX1 & 1272 & 230 & 153 & 889 & 0 & 0.67 & 1885 \\
\hline $\mathrm{CX} 2$ & 68 & 48 & 21 & 0 & 0 & 0.20 & 337 \\
\hline $\mathrm{CX} 3$ & 0 & 0 & 0 & 0 & 0 & 0.00 & 0 \\
\hline BY1 & 3095 & 744 & 544 & 142 & 1666 & 0.65 & 4771 \\
\hline BY2 & 2149 & 681 & 131 & 0 & 1337 & 0.54 & 4011 \\
\hline BY3 & 1090 & 323 & 531 & 236 & 0 & 0.50 & 2313 \\
\hline BY4 & 548 & 170 & 378 & 0 & 0 & 0.41 & 1348 \\
\hline BY5 & 433 & 280 & 153 & 0 & 0 & 0.37 & 1472 \\
\hline AX1-W & 1354 & 504 & 504 & 341 & 509 & 0.37 & 3619 \\
\hline AX2-W & 1494 & 430 & 76 & 576 & 412 & 0.51 & 2921 \\
\hline AX3-W & 911 & 373 & 395 & 143 & 0 & 0.34 & 2720 \\
\hline BX1-W & 1093 & 458 & 448 & 186 & 0 & 0.37 & 3019 \\
\hline BX2-W & 589 & 226 & 124 & 0 & 0 & 0.35 & 1739 \\
\hline$* \mathrm{BX} 3-\mathrm{W}$ & - & - & - & - & - & - & - \\
\hline CX1-W & 1300 & 770 & 241 & 0 & 388 & 0.33 & 4189 \\
\hline CX2-W & 190 & 190 & 0 & 0 & 0 & 0.18 & 1064 \\
\hline${ }^{*} \mathrm{CX} 3-\mathrm{W}$ & - & - & - & - & - & - & - \\
\hline BY1-W & 1519 & 702 & 286 & 532 & 0 & 0.36 & 4225 \\
\hline BY2-W & 1282 & 690 & 592 & 0 & 0 & 0.31 & 4164 \\
\hline BY3-W & 734 & 440 & 284 & 0 & 0 & 0.28 & 2695 \\
\hline
\end{tabular}

Denotation: A, B, C $=4 \mathrm{~mm}, 6 \mathrm{~mm}, 8 \mathrm{~mm} \mathrm{X}, \mathrm{Y}=\varphi 13.4 \mu \mathrm{m}, \varphi 26.8 \mu \mathrm{m}$

*BX3 and CX3 showed no cracking, so cracking tests of BX3-W and CX3-W were not performed.

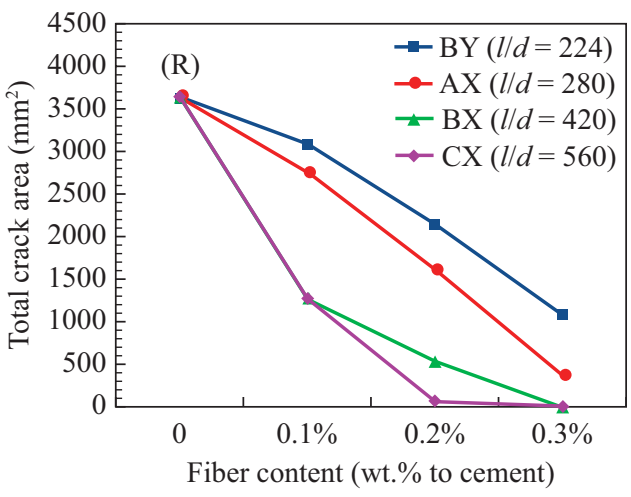

Fig. 6. Effect of fiber content on the total crack area.

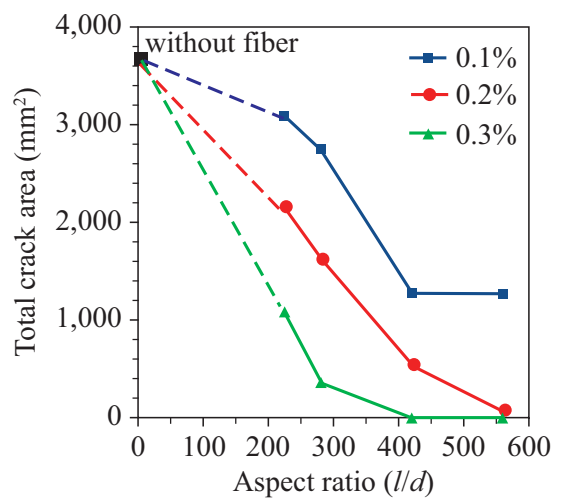

Fig. 7. Effect of fiber aspect ratio on the total crack area.

\section{Influence of Fiber Content and Fiber Aspect Ratio on the Averge Crack Width}

The ACW for a plate specimen was calculated by dividing the total crack area (TCA) by the total line crack length (Ln) as indicated in Eq. (1). The ACW was effectively reduced in the specimens with fiber and the reduction efficiency depended on 


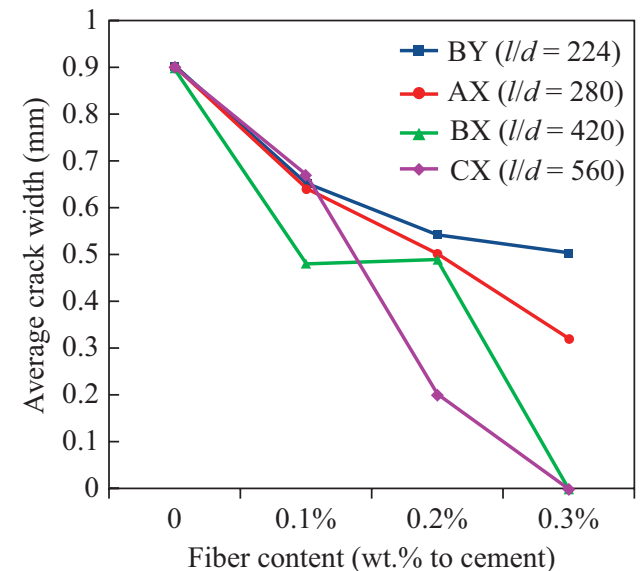

Fig. 8. Effect of fiber content on ACW.

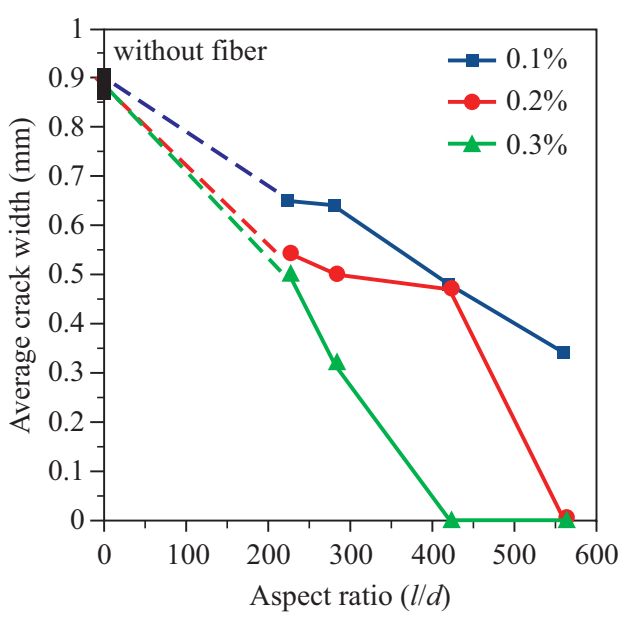

Fig. 9. Effect of fiber aspect ratio on ACW.

the fiber content as shown in Fig. 8. With the inclusion of $0.1 \%$ fiber, regardless the aspect ratio, the ACW reduced dramatically from the $0.9 \mathrm{~mm}$ of the control mixture $(\mathrm{R})$ to about $0.5-0.7 \mathrm{~mm}$ as depicted in Fig. 8. However, as $0.2 \%$ fiber was added, the ACW of BY, BX, and AX reduced moderately or remained at $0.5 \mathrm{~mm}$. Only the $\mathrm{CX}$ fiber, which had the largest aspect ratio, reduced further to $0.15 \mathrm{~mm}$. The ACW of BY, AX, BX, and CX became $0.5 \mathrm{~mm}, 0.3 \mathrm{~mm}$. $0 \mathrm{~mm}$, and $0 \mathrm{~mm}$, respectively when $0.3 \%$ fiber was added.

It was noted that the development of ACW was significantly affected by the aspect ratio of the fiber as exhibited in Fig. 9. The ACW of BY, which had the least aspect ratio of 224 , remained constantly at the highest level, while the $C X$, in comparison with other fibers, had the least ACWs. The ACW results suggested that the fiber content and the aspect ratio of fiber also significantly affect the crack propagation resulting form the crack-bridging effect provided by the numerous randomly distributed discrete fibers $[12,13]$.

\section{Influence of Fiber Content and Fiber Aspect Ratio on the Crack Area Distribution Categorized by Crack Width}

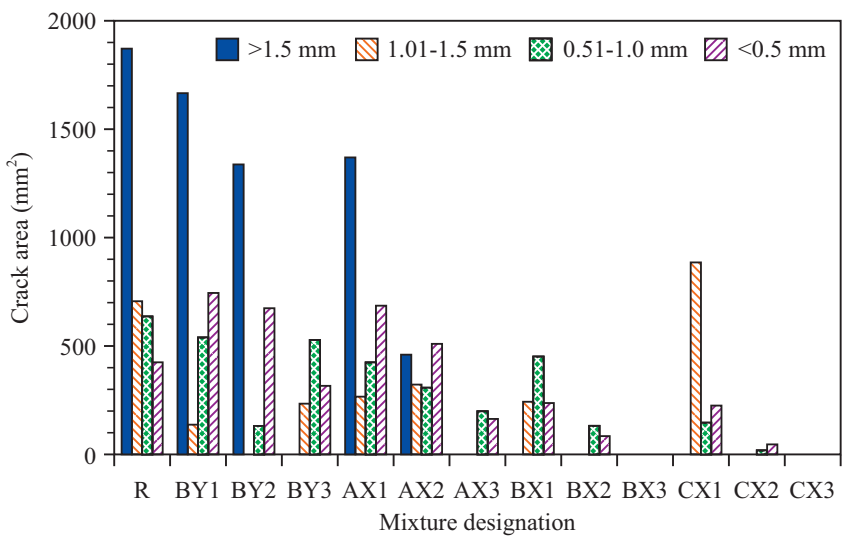

Fig. 10. Effect of fiber on the crack area distribution.

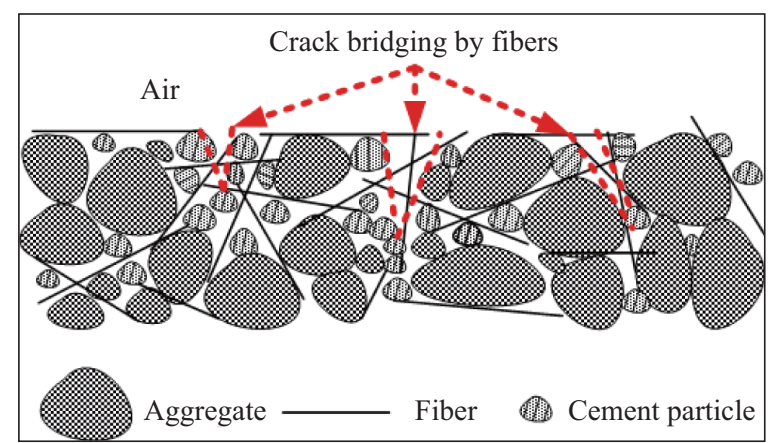

Fig. 11. Schematic illustration of plastic shrinkage crack bridging by fibers.

The computed line crack widths were categorized into four groups as listed in Table 4 and exhibited in Fig. 10.

For the BY1 and AX1 mixtures with the inclusion of $0.1 \%$ fiber, the crack areas in group $1(>1.5 \mathrm{~mm})$ were moderately reduced. Yet, no crack lines with width larger than $1.5 \mathrm{~mm}$ were observed for the mixtures of BX1, BX2, BX3, CX1, CX2, and $\mathrm{CX} 3$. The crack width was recognized to have influence on the corrosion rate of rebar in the concrete structure due to the fact that aggressive chemicals, water, and oxygen could penetrate into concrete more easily. As a result, reducing large cracks could extend the service life of concrete structures. On the whole, the crack areas in group 1 (crack widths $>1.5 \mathrm{~mm}$ ) were significantly reduced with the inclusion of fibers and the reduction capability was significantly affected by the fiber content as depicted in Fig. 10. The trend of crack area reduction in group 1 continued as $0.2 \%$ fiber was added. And with the inclusion of $0.3 \%$ fiber, all mixtures did not exhibit any cracks in group 1 . These results implied that the effect of fiber content on inhibiting large cracks was pronounced. In addition, with the same fiber content, fibers with high aspect ratio such as $l / d=420(\mathrm{BX})$ and $l / d=560(\mathrm{CX})$ were found to be more effective in reducing large cracks than those of $l / d=224$ (BY) and $l / d=280(\mathrm{AX})$. This might be attributed to cracking-bridging capacity provided by an extra number of fibers or longer fibers as illustrated in Fig. 11. 


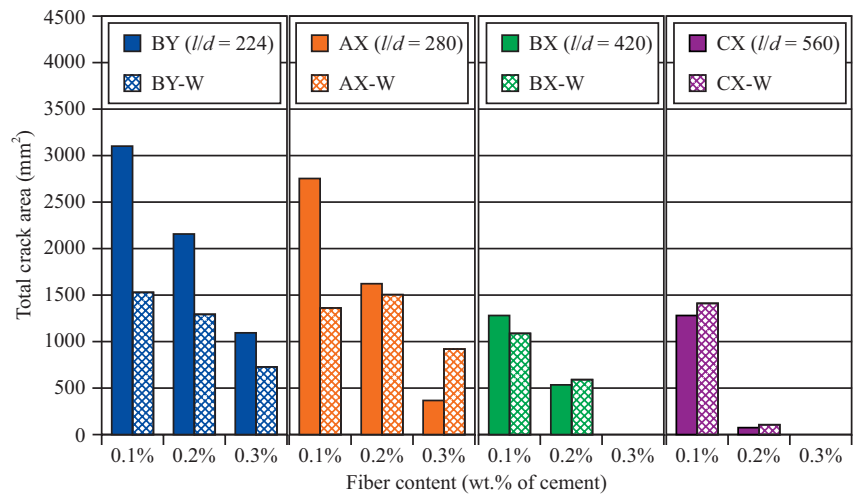

Fig. 12. Effect of WSP and fiber on the total crack area.

\section{Influence of WSP and Fiber on the Total Crack Area and the Average Crack Width}

When cellulosed based WSP (CE) contacts water, it dissolves to form a viscous solution. CE such as MC, MHEC, and HPMC has been used in many applications including wallpaper glue and the binder for tablet or ceramics. CE is also an indispensable admixture in dry mortar products such as tile adhesive and plaster to increase adhesion [8]. With the addition of WSP to fiber reinforced specimen, the reduction of TCA responded differently according to the fiber content and fiber aspect ratio as depicted in Fig. 12.

The efficiency on reducing TCA seems to be effective for the mixtures with low aspect ratio fibers or lower fiber content such as $l / d=224$ (BY) fibers at 0.1-0.3\% fiber content and $l / d=280(\mathrm{AX})$ at $0.1 \%$ fiber content which, may have resulted from the effective increase of bond strength between fibers and cementitious matrix provided by WSP. The micrograph depicted in Fig. 13 reveals that fibers in the specimen without WSP remained neat and clean. Yet, bonded mortars were found on the fiber surface in the specimen with WSP as depicted in Fig. 14.

For the specimens with large aspect ratio fibers $(l / d=420$ and 560) or greater fiber content, the effect of WSP on TCA is not as pronounced as those mixtures with fiber aspect ratio less than $420(l / d<420)$, which may be due to the fact that the effect of increasing bond strength provided by WSP on reducing cracks seems much weaker in comparison with the effect of decreasing fiber spacing resulting from a greater number of fibers and effect of crack-bridging capacity provided by long fibers [12, 13]. Therefore, little synergistic effect on reducing TCA was found in BX-W, CX-W, and some of the AX-W mixtures as shown in Fig. 12.

Nevertheless, the effect of WSP on the average crack width reduction was pronounced as illustrated in Fig. 15. All mixtures showed a significant reduction of ACW except for AXW at $0.2 \%$ and $0.3 \%$ which remained at the similar reduction level as that of AX mixtures. This disparity was mainly caused by the increasing crack area of group 2 (crack width between $0.5-1.01 \mathrm{~mm}$ ) in AX-W mixtures as demonstrated in Table 4. The significant synergistic effect on reducing the

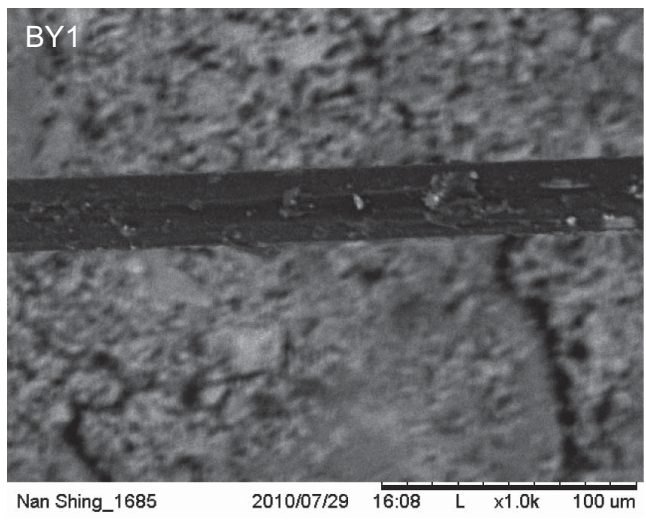

Fig. 13. Micrograph of fiber reinforced specimen without WSP.

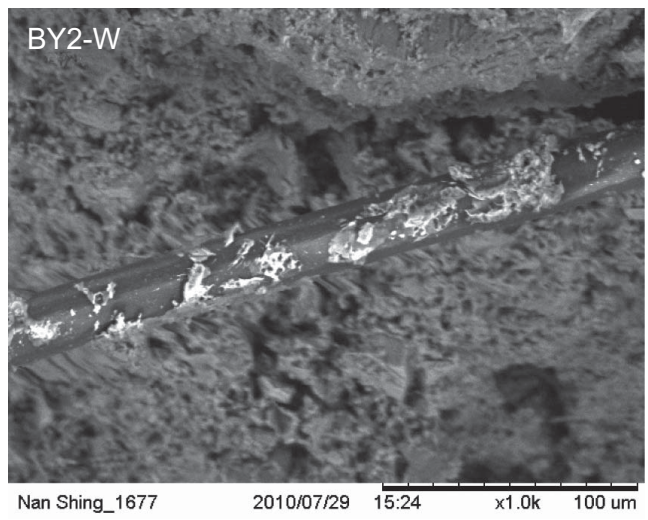

Fig. 14. Micrograph of fiber reinforced specimen with WSP.

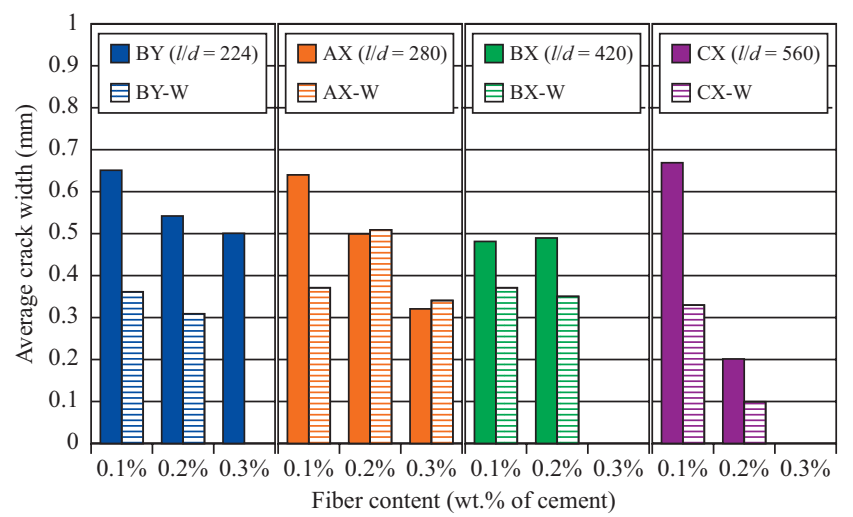

Fig. 15. Effect of fiber and WSP on ACW.

average crack width may have resulted from the polymer film formation and the deposition of fine particles on the drying front when WSP [4] was being added as illustrated in Fig. 16.

\section{Influence of WSP and Fiber on the Crack Width Distribution}

WSP not only reduced the total crack area and the average crack width, but also reduced cracks wider than $1.5 \mathrm{~mm}$ as illustrated in Fig. 17. 


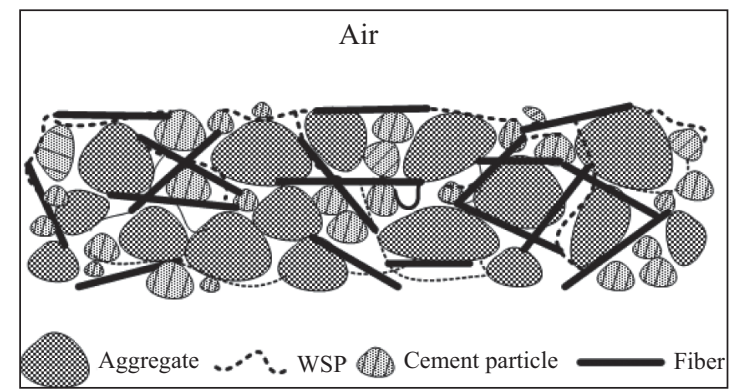

Fig. 16. Schematic illustration of WSP film and fiber in the cementitious composite.

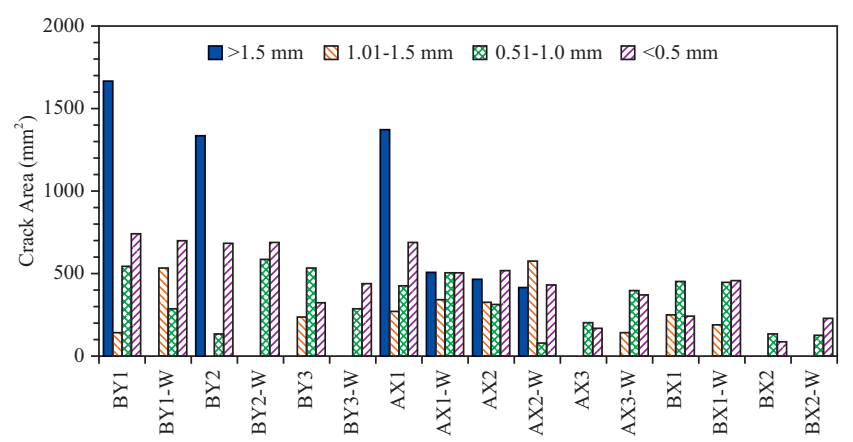

Fig. 17. Effect of WSP and fiber on the crack width distribution.

WSP, when used in combination with BY $(l / d=224)$ fibers, eliminated cracks in group $1(>1.5 \mathrm{~mm})$ completely, whilst with $\mathrm{AX}(l / d=280)$ reduced from $1370 \mathrm{~mm}^{2}$ (AX1) to 509 $\mathrm{mm}^{2}$ (AX1-W). Nevertheless, diminishing effect of reducing cracks in group $1(>1.5 \mathrm{~mm})$ was observed in AX2 $\left(466 \mathrm{~mm}^{2}\right)$ to $\mathrm{AX} 2-\mathrm{W}\left(412 \mathrm{~mm}^{2}\right)$. This efficiency of reducing large cracks may have resulted from the availability of polymer film formation on the drying front so that crack widths were reduced [9]. It can be concluded the combined use of WSP and fibers with low aspect ratio fibers $(l / d=224$ and 280) exhibited a synergistic reduction of cracks wider than $1.5 \mathrm{~mm}$ and the efficiency on reducing TCA and ACW. For example, the crack reduction of $\mathrm{BY} 1-\mathrm{W}$ was similar to those of $\mathrm{AX} 2$ and AX3. In practical terms, prevention of early-age shrinkage cracking by addition of WSP, not only reduces fiber content but may also keep the mixture workable.

\section{CONCLUSIONS}

The results of the early-age crack resistance in terms of the total crack area, the average crack width, and crack width distribution are as follows:

1. The early-age crack resistance increased with increasing fiber content, regardless of the fiber aspect ratio.

2. With the same content of fiber, higher aspect ratio yields better early-age crack resistance. In other words, longer fibers with the same diameter and finer fibers with equal length provided better crack resistance.

3. In general, WSP, when used in combination with $0.1-0.2 \%$ fiber content (wt\% to cement) illustrated synergistic effect on reducing the total crack area and the average crack width by increasing fiber-matrix bond strength.

4. In specimens with $0.3 \%$ fibers or with fibers having aspect ratio greater than 420, WSP showed an insignificant reduction of the total crack area. The potential benefit of increasing fiber-matrix bond strength and polymer film formation by WSP might be masked by decreasing fiber spacing with an extra number of fibers.

\section{ACKNOWLEDGMENTS}

We would like to gratefully acknowledge the National Science Council for the financial support (NSC 96-2622E019-005-cc3).

\section{REFERENCES}

1. ACI Committee 360, "Chapter 10 Fiber-reinforced concrete slabs-on ground," Design of Slabs-on-Ground (ACI 360R-06), American Concrete Institute, Farmington Hills, MI (2006).

2. ASTM C1579-06, "Standard test method for evaluating plastic shrinkage cracking of restrained fiber reinforced concrete (using a steel form insert)," American Society for Testing and Materials, West Conshohocken, PA (2006)

3. Bentz, D. P., "Curing with shrinkage-reducing admixtures," ACI Concrete International, Vol. 27, No. 10, pp. 55-60 (2005).

4. Bentz, D. P., Peltz, M. A., Snyder, K. A., and Davis, J. M., "VERDiCT: viscosity enhancers reducing diffusion in concrete technology," ACI Concrete International, Vol. 31, No. 1, pp. 31-36 (2009).

5. Chen, P.-W., Fu, X., and Chung, D. D. L., "Microstructural and mechanical effects of latex, methylcellulose, and silica fume on carbon fiber reinforced cement," ACI Materials Journal, Vol. 94, No. 2, pp. 146-155 (1997).

6. Chu, T.-J., Robertson, R. E., Najm, H., and Naaman, A. E., "Effects of poly(vinyl alcohol) on fiber cement interfaces. Part II: microstructures," Advanced Cement Based Materials, Vol. 1, No. 3, pp. 122-130 (1994).

7. Fu, X. and Chung, D. D. L., "Improving the bond strength of concrete to reinforcement by adding methylcellulose to concrete," ACI Materials Journal, Vol. 95, No. 5, pp. 601-608 (1998).

8. Hoechst A. G., Marketing Alkylose/Dispersionpulver, Modern and Efficient Building with Tylose and Auxiliaries, Frankfurt am Main, Germany, (1996).

9. Lin, S.-T. and Huang, R., "Effect of viscosity modifying agent on plastic shrinkage cracking of cementitious composites," Materials and Structures, Vol. 43, No. 5, pp. 651-664 (2010).

10. Lin, S.-T., Huang, R., and Chang, C. Y., "Effect of water soluble polymers on the early age shrinkage of cementitious composites by using the ring test method," Material Chemistry and Physics, Vol. 121, No. 3, pp. 440446 (2010).

11. Lin, S.-T., Huang, R., and Weng, T.-L., "Effect of mineral admixtures and viscosity modifying admixtures on plastic shrinkage cracking of cementitious composites," Journal of the Chinese Institute of Engineers, Vol. 2, No. 2, pp. 287-297 (2011).

12. Metha, P. and Monteiro, P., Concrete: Microstructure, Properties, and Materials, 3rd Edition, McGraw Hill Education, New York (2004).

13. Mindess, S., Young J. F., and Darwin, D., Concrete, 2nd Edition, Prentice Hall, Pearson Education Inc., Upper Saddle River, NJ (2002).

14. Naaman, A. E., Wongtanakitcharoen, T., and Hauser, G., "Influence of different fibers on plastic shrinkage cracking of concrete," ACI Materials 
Journal, Vol. 102, No. 1, pp. 49-58 (2005).

15. Najm, H., Naaman, A. E., Chu, T.-J., and Robertson, R. E., "Effects of poly(vinyl alcohol) on fiber cement interfaces. Part I: bond stress-slip response," Advanced Cement Based Materials, Vol. 1, No. 3, pp. 115-121 (1994).

16. Retrieved Sep. 15, 2010 from http://www.dolan-gmbh.com/service/images/
Dolanit_Produktmappe.pdf.

17. Shin-Etsu Chemical Co., Ltd., Cellulose Dept., Metolose Water-Soluble Cellulose Ether, Tokyo, Japan (1998).

18. Xu, Y. and Chung, D. D. L., "Reducing the drying shrinkage of cement paste by admixture surface treatments," Cement and Concrete Research, Vol. 30, No. 2, pp. 241-245 (2000). 